\title{
Molecular and functional characterization of cionin receptors in the ascidian, Ciona intestinalis: the evolutionary origin of the vertebrate cholecystokinin/gastrin family
}

\author{
Toshio Sekiguchi, Michio Ogasawara ${ }^{1}$ and Honoo Satake \\ Suntory Foundation for Life Sciences Bioorganic Research Institute, Wakayamadai 1-1-1, Shimamoto-cho, Mishima-gun, Osaka 618-8503, Japan \\ ${ }^{1}$ Department of Nanobiology, Graduate School of Advanced Integration Science, Chiba University, 1-33 Yayoi-cho, Inage-ku, Chiba 263-8522, Japan \\ (Correspondence should be addressed to H Satake; Email: sateke@sunbor.or.jp)
}

\begin{abstract}
Cholecystokinin (CCK) and gastrin are vertebrate brain-gut peptides featured by a sulfated tyrosine residue and a C-terminally amidated tetrapeptide consensus sequence. Cionin, identified in the ascidian, Ciona intestinalis, the closest species to vertebrates, harbors two sulfated tyrosines and the $\mathrm{CCK} /$ gastrin consensus tetrapeptide sequence. While a putative cionin receptor, cior, was cloned, the ligand-receptor relationship between cionin and CioR remains unidentified. Here, we identify two cionin receptors, CioR1 and CioR2, which are the aforementioned putative cionin receptor and its novel paralog respectively. Phylogenetic analysis revealed that CioRs are homologous to vertebrate CCK receptors (CCKRs) and diverged from a common ancestor in the Ciona-specific lineage. Cionin activates intracellular calcium mobilization in cultured cells expressing CioR1 or CioR2. Monosulfated and
\end{abstract}

nonsulfated cionin exhibited less potent or no activity, indicating that CioRs possess pharmacological features similar to the vertebrate CCK-specific receptor CCK1R, rather than its subtype CCK2R, given that a sulfated tyrosine in CCK is required for binding to CCK1R, but not to CCK2R. Collectively, the present data reveal that CioRs share a common ancestor with vertebrate CCKRs and indicate that CCK and CCK1R form the ancestral ligand-receptor pair in the vertebrate $\mathrm{CCK} /$ gastrin system. Cionin is expressed in the neural complex, digestive organs, oral siphon and atrial siphons, whereas the expression of ciors was detected mainly in these tissues and the ovary. Furthermore, cioninergic neurons innervate both of the siphons. These results suggest that cionin is involved in the regulation of siphonal functions.

Journal of Endocrinology (2012) 213, 99-106

\section{Introduction}

Cholecystokinin (CCK) and gastrin are vertebrate brain-gut peptides. CCK is released mainly from the I cells of the small intestine and induces gallbladder contraction and pancreatic enzyme secretion in mammals (Folsch et al. 1978, Sonobe et al. 1995). Furthermore, CCK is expressed in the central and peripheral nervous system and is implicated in neural functions such as food intake, sleep and memory (Crawley \& Corwin 1994, Moran \& Schwartz 1994). Gastrin is produced in the $G$ cells of mammalian antral mucosa and induces gastric acid secretion (Dockray 2004). In mammals, CCK possesses a sulfated tyrosine at position 7 from the $\mathrm{C}$ terminus, whereas a sulfated tyrosine is located at position 6 from the $\mathrm{C}$ terminus of gastrin. Moreover, CCK and gastrin share the four-amino acid C-terminal consensus sequence (Trp-Met-Asp-Phe- $\mathrm{NH}_{2}$ ), which is essential for receptor activation. Such structural conservation suggests that CCK and gastrin evolved from a common ancestor (Johnsen 1998). Nonmammalian CCK and gastrin have also been identified (Fan et al. 1987, Johnsen 1994, Wu et al. 1995, Johnsen et al. 1997, Kurokawa et al. 2003). Both

peptides also possess the common C-terminal tetrapeptide and a sulfated tyrosine at position 7 from the $\mathrm{C}$ terminus, indicating that nonmammalian gastrin is more similar to mammalian CCK than to mammalian gastrin.

An ascidian, Ciona intestinalis, belongs to urochordates, which is a sister subphylum of vertebrates (Delsuc et al. 2006, Putnam et al. 2008). Johnsen \& Rehfeld (1990) purified an octapeptide named cionin as a candidate of CCK/gastrin family peptide from adult $C$. intestinalis cerebral ganglion. Cionin conserves the C-terminal amidated tetrapeptide of vertebrate CCK/gastrin and possesses sulfated tyrosines at positions 6 and 7 from the $\mathrm{C}$ terminus. Moreover, cionin stimulates the contraction of rainbow trout gallbladders and the release of histamine and gastric acid in the rat stomach, implying that cionin exerts activity similar to CCK and gastrin activity in the vertebrate organs (Marvik et al. 1994, Schjoldager et al. 1995). Consequently, these characteristics suggest that cionin is a hybrid peptide of CCK and gastrin and a putative ancestor of vertebrate CCK/gastrin family peptides (Monstein et al. 1993).

CCK and gastrin exert their activities through specific interaction with two cognate receptors, CCK1 (CCK1R) and 
CCK2R (Dufresne et al. 2006). CCK1R is a CCK-specific receptor, and sulfation of $\mathrm{CCK}$ is required for binding to CCK1R. In contrast, CCK2R recognizes both CCK and gastrin, and sulfation of these peptides is not necessary for its ligand recognition. In $C$. intestinalis, a putative cionin receptor, cior, was cloned from the gastrointestinal tract (Nilsson et al. 2003). Cionin receptor (CioR) showed high sequence homology with mammalian, chicken and Xenopus CCK receptors (CCKRs). However, previous studies provided no evidence that cionin binds to and activates CioR, which cannot exclude the possibility that CioR is not an endogenous receptor for cionin. Furthermore, the tissue distribution of cionin and its receptor is yet to be investigated. To address these issues, we describe the molecular and functional characterizations of two cionin receptors, CioR 1 and CioR2. CioR1 is the aforementioned putative cionin receptor, and CioR 2 is a novel cionin receptor paralog. This study reveals the primary sequences, pharmacological features, and tissue distribution of both CioRs and localization of cionin, which provides a novel evolutionary scenario of vertebrate $\mathrm{CCK} /$ gastrin receptors.

\section{Materials and Methods}

\section{Animals}

Adult $C$. intestinalis were cultivated and collected at the Maizuru Fisheries Research Station of Kyoto University and maintained in seawater at $18^{\circ} \mathrm{C}$.

\section{Cloning of cior2}

Total RNA $(2 \mu \mathrm{g})$ from the neural complex was reverse transcribed to the template cDNA at $55^{\circ} \mathrm{C}$ for 60 min using the oligo(dT) anchor primer and SuperScript III RNase $\mathrm{H}^{-}$Reverse Transcriptase (Invitrogen). The partial CioR2 sequence was obtained by PCR using the primers identical to nucleotides (nt) 502-521 and complementary to nt 721-740. The transcriptional start site was identified using the 5'-RACE System for Rapid Amplification of cDNA Ends, Version 2.0 (Invitrogen). Template cDNA was synthesized using primer complementary to nt 606-625 and amplified using the anchor primer and primer complementary to nt 472-491. The first PCR products were reamplified using the anchor primer and primer complementary to nt 320-339. Both the first and the second PCR were performed as follows: 5 min at $94{ }^{\circ} \mathrm{C}, 35$ cycles for $30 \mathrm{~s}$ at $94{ }^{\circ} \mathrm{C}, 30 \mathrm{~s}$ at $52{ }^{\circ} \mathrm{C}$ and $2 \mathrm{~min}$ at $72^{\circ} \mathrm{C}$ (7 min for the last cycle). The second PCR products were subcloned. The $3^{\prime}-\mathrm{UTR}$ was determined using $3^{\prime}$-RACE System for Rapid Amplification of cDNA Ends (Invitrogen). The first PCR was performed using the anchor primer and primer identical to nt 1344-1363. The second PCR was performed using the anchor primer and a primer identical to nt 1456-1475. Both the first and the second PCR were performed under the following conditions: $5 \mathrm{~min}$ at

$94^{\circ} \mathrm{C}, 35$ cycles of $30 \mathrm{~s}$ at $94^{\circ} \mathrm{C}, 30 \mathrm{~s}$ at $50{ }^{\circ} \mathrm{C}, 2 \mathrm{~min}$ at $72{ }^{\circ} \mathrm{C}$ ( $7 \mathrm{~min}$ for the last cycle). The second PCR products were subcloned. All subcloned inserts were sequenced on an ABI PRISM 3130 Genetic Analyzer using a Big-Dye sequencing kit version 3.1 (Applied Biosystems, Foster City, CA, USA) and universal primers (SP6 and T7 primers). The nucleotide sequence reported in this paper has been submitted to the DDBJ/GenBank/EBI Data Bank with the accession number AB669183.

\section{Phylogenetic analysis of CioRs}

Phylogenetic analysis was performed as described previously (Sekiguchi et al. 2007, 2009). The amino acid sequences encoding TM domains of CioRs were aligned with the corresponding amino acid sequence of CCK1R, CCK2R and orexin receptor-type 1 (OX1R) using the CLUSTAL program (Higgins \& Sharp 1988) and the alignment was verified manually. After removing gaps, the alignments were used to construct phylogenetic trees. The trees were calculated using the MEGA4 program based on the neighbor-joining method (Saitou \& Nei 1987, Tamura et al. 2007). The sequences used were as follows: P3223.1; Homo sapiens (human) CCK2R, Q3ZB46; Mus musculus (mouse) Cck2r, NP_001001742; Gallus gallus (chicken) Cck2r, P70031; Xenopus laevis (African clawed frogs) Cck-xlr, XP_002663361; Danio rerio (zebrafish) Cckr-like, B0R0R2; zebrafish, similar to vertebrate cckr, XP_697493; zebrafish CCK1R-like, NP_001074970; chicken Cck1r, P32238; human CCK1R, O08786; mouse Cck1r, XP_782630; Strongylocentrotus purpuratus (sea urchin) similar to CioR protein, AAF48879; Drosophila melanogaster (fruit fly) Cckr-17d3, NP_491918.2; Caenorhabditis elegans (nematode) Ckr-1, ACA81683.1; nematode Ckr-2a, ACA81684.1; nematode Ckr-2b, O43613; and human OX1R.

\section{RT-PCR of the cionin, cior 1 and cior $2 m R N A s$}

All primers for RT-PCRs are described in Table 1. Total RNA $(2 \mu \mathrm{g})$ extracted from various tissues were reverse transcribed using Superscript III (Invitrogen) and oligo $(\mathrm{dT})_{20}$ primer. The PCR was performed under the following conditions: $94{ }^{\circ} \mathrm{C}$ for $1 \mathrm{~min}, 35$ cycles of $94{ }^{\circ} \mathrm{C}$ for $30 \mathrm{~s}$, $60{ }^{\circ} \mathrm{C}$ for $30 \mathrm{~s}$, and $72{ }^{\circ} \mathrm{C}$ for $1 \mathrm{~min}$, and final extension of $72{ }^{\circ} \mathrm{C}$ for $7 \mathrm{~min}$. The PCR products were resolved in $1.5 \%$

Table 1 Primer sequences

Primer name (position)

Cionin-FW (9-28)

Cionin-RV (312-321)

CioR1-FW (2-21)

CioR1-RV (643-662)

CioR2-FW (6-25)

CioR2-RV (417-436)

\begin{abstract}
Sequence
5'-GAAGCGTCGGTGATTGGTTT-3'

5'-AAAGCTGTTTGCCTGGTAGC- $3^{\prime}$

5'-GCTGCTCGCTAAGAAAAGGA-3'

$5^{\prime}$-TTCCTGCAGTCGAAAGCGTA- ${ }^{\prime}$

5'-CGTGTTCTGTATGGCAATGG- $3^{\prime}$

5'-AGCATCGACCGATCTTCACT-3'
\end{abstract}


agarose gel. Amplified fragments were confirmed by sequence analysis.

\section{Peptide synthesis}

Cionin, its derivatives, and Drosophila sulfakinin 1 (DSK1) were synthesized using an ABI 430A solid-phase peptide synthesizer (Applied Biosystems), the Fast Moc method and Fmoc-Tyr $\left(\mathrm{SO}_{3}\right)$ according to the manufacturer's instruction.

\section{Calcium accumulation assay}

HEK293-MSR cells (Invitrogen) were grown under 5\% $\mathrm{CO}_{2}$ and $100 \%$ relative humidity in DMEM medium supplemented with $10 \%(\mathrm{v} / \mathrm{v})$ fetal bovine serum and $0.1 \mathrm{mM}$ nonessential amino acids. Each CioR open reading frame-containing pcDNA 6/myc-His plasmid or empty vector was transfected into HEK293-MSR cells using Lipofectamine 2000 (Invitrogen) according to the manufacturer's instructions, and the cells were incubated for $48 \mathrm{~h}$. For measurement of ligand-induced intracellular calcium ion, cells were loaded for $60 \mathrm{~min}$ with $\mathrm{Ca} 3$ fluorescent calcium indicator mixture (Molecular Devices, Sunnyvale, CA, USA) $48 \mathrm{~h}$ after transfection. Various concentrations of cionin and its synthetic derivatives were administrated to the cells in a FlexStation II-automated apparatus (Molecular Devices). Real-time fluorescent kinetics at excitation wavelength $485 \mathrm{~nm}$ and emission wavelength $525 \mathrm{~nm}$ were observed for $3 \mathrm{~min}$ using FlexStation II. All values displayed are the mean \pm s.E.M. of at least three experiments. The concentration-response was analyzed using the Prism 3.03 software (GraphPad software, La Jolla, CA, USA) to estimate the $\mathrm{EC}_{50}$ value.

\section{In situ hybridization}

The cionin cDNA clone (nt 1-508) was used to synthesize DIG-labeled RNA probe using a DIG RNA labeling kit (Roche Applied Science). Whole mount in situ hybridization of the juvenile and adult neural complex was performed as described previously (Ogasawara et al. 2002). No positive signals were observed using sense probes, confirming the specificity of hybridization.

\section{Antibody}

The four-amino acid peptide (Trp-Met-Asp-Phe- $\mathrm{NH}_{2}$ ) of the cionin conjugated with keyhole limpet hemocyanin was used as respective antigen (Operon Biotechnologies, Tokyo, Japan). An anticionin serum was raised in rabbit, and a cionin antibody was purified using synthetic cionin antigen peptide (Operon Biotechnologies).

\section{Immunohistochemistry of the neural complex}

The neural complex was dissected from adult $C$. intestinalis and fixed with Bouin's solution overnight. Fixed specimens were dehydrated through a graded ethanol series, embedded in paraffin, and sectioned at $6 \mu \mathrm{m}$ thickness. After deparaffinzation, the sections were washed with PBS and incubated in $1 \%$ normal horse serum and $0 \cdot 4 \%$ Triton X-100 in PBS (TNBS) at room temperature for $1 \mathrm{~h}$. The sections were then incubated with anticionin rabbit antibody diluted 1:500 in TNBS at $4{ }^{\circ} \mathrm{C}$ overnight and washed four times with PBS for $5 \mathrm{~min}$. Subsequently, the sections were incubated with biotinconjugated donkey antirabbit IgG diluted 1:1000 in PBS at room temperature for $1 \mathrm{~h}$. After the sections were rinsed four times with PBS for $5 \mathrm{~min}$, they were incubated with avidinbiotinylated HRP complex (ABC, Vector Laboratories, Inc., CA, USA) for $30 \mathrm{~min}$. The color reaction was developed by

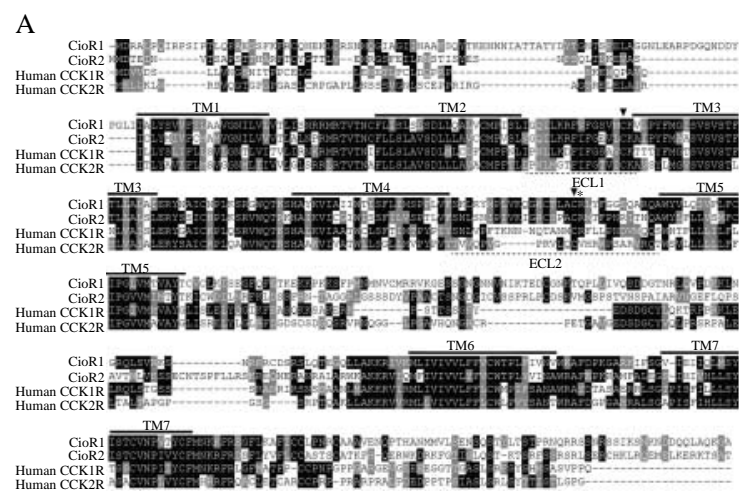

B

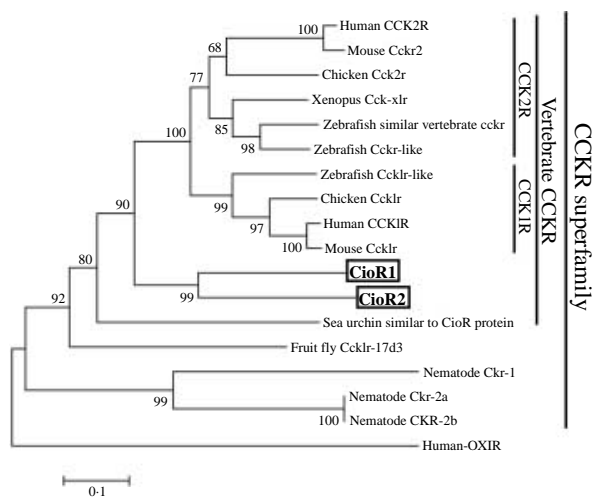

Figure 1 Characterization of CioRs. (A) Alignment of amino acid sequences of CioRs and human CCKRs. Identical and similar amino acid sequences among at least three members are indicated by black and gray boxes respectively. The predicted seven-transmembrane domains are indicated by lines. Dotted lines indicate extracellular loop 1 (ECL1) and extracellular loop 2 (ECL2). The two cysteine residues, which form a disulfide bond between extracellular loops 1 and 2, are denoted by arrowheads. The arginine residue that recognizes sulfated tyrosine of CCK is shown by an asterisk. (B) Molecular phylogenetic tree of the CCKR family constructed using the neighbor-joining method. The number beside each branch indicates the percentage of times that a node was supported in 1000 bootstrap pseudoreplications. Human orexin receptor-type 1 (OX1R) was used as an outgroup. The unrooted tree is shown as a rooted tree for simplicity. CioRs are indicated in boldface and boxed. The scale bar indicates an evolutionary distance of $0 \cdot 1$ amino acid substitutions per protein. 
incubation in $0.02 \% 3$,3-diaminobenzidine-tetrachloride mixed with $0.06 \%$ hydrogen peroxide in $0.05 \mathrm{M}$ Tris $-\mathrm{HCl}$, $\mathrm{pH} 7 \cdot 6$, for $2-3 \mathrm{~min}$. Finally, the sections were mounted in Mount-Quick (Daido Sangyou, Saitama, Japan) and observed by light microscopy. Pretreatment of the antibody with peptides was conducted by incubating diluted antibody (1:500) with cionin peptide $(50 \mu \mathrm{g} / \mathrm{ml})$ at $4{ }^{\circ} \mathrm{C}$ for $24 \mathrm{~h}$. Immunostaining using the resultant cionin-absorbed antibody detected no signal, confirming the specificity of the antibody.

\section{Whole mount immunohistochemistry of the juveniles}

C. intestinalis juveniles were fixed with $10 \%$ formalin in artificial seawater at $4{ }^{\circ} \mathrm{C}$ overnight. The specimens were washed with T-PBS $(0 \cdot 1 \%$ TritonX-100 in PBS) and incubated with blocking buffer (1\% BSA in PBS) at room temperature for $1 \mathrm{~h}$. After blocking treatment, the juveniles were incubated with anticionin rabbit antibody diluted 1:500 with blocking buffer at $4{ }^{\circ} \mathrm{C}$ overnight and washed three times with PBT $(0 \cdot 1 \%$ Tween in PBS) for $20 \mathrm{~min}$. Subsequently, they were incubated with Alexa 488-conjugated goat rabbit IgG (Invitrogen) diluted 1:1000 in blocking buffer and washed three times with PBT for $20 \mathrm{~min}$. The specimens were rinsed several times with $\mathrm{PBT}$ and mounted in $50 \%$ glycerol. Immunoreactivity was detected using a FLUOVIEW FV1000 confocal microscope (Olympus, Tokyo, Japan). Immunostaining using the cionin-absorbed antibody detected no signal, confirming the specificity of the antibody.

\section{Results}

\section{Molecular characterization of CioR2}

A putative cionin receptor, CioR, has already been reported to display a high similarity to vertebrate CCKRs (Nilsson et al. 2003). To explore other putative cionin receptors, C. intestinalis genome database (http://ghost.zool.kyoto-u.ac.jp/blast_kh. html) was searched using the tblastn function and the CioR amino acid sequence as a query. The entry KH.C14.565.v1.B.ND1-1 was retrieved as a possible candidate. The full-length sequence of this cior-like gene was determined by RT-PCR and RACE from the adult C. intestinalis neural complex. The deduced 498-amino acid sequence was shown to harbor seven hydrophobic transmembrane regions (Fig. 1A). A sequence comparison revealed that this protein displayed 59 and $58 \%$ similarity with human CCK1R and CCK2R respectively. Additionally, CioR showed 62 and 59\% sequence similarity with human CCK1R and CCK2R respectively. We thus designated CioR and its novel receptor candidates as CioR 1 and CioR2. Alignment of CioRs and human CCKRs demonstrated that two cysteine residues between the first and the second extracellular loops are conserved (Fig. 1A). Moreover, an arginine residue in extracellular loop 2, which is responsible for CCK1R binding to sulfated tyrosine of CCK, was conserved in CioRs and CCK1R but not in CCK2R (Fig. 1A).
Phylogenetic analysis revealed that CioR1 and CioR2 placed at the base of the clade are formed by vertebrate CCKRs with high bootstrap value, indicating that both receptors are orthologous to vertebrate CCKRs and were duplicated in the C. intestinalis-specific lineage (Fig. 1B). These results verified that CioR1 and CioR2 might have generated via a gene duplication in the C. intestinalis lineage, but the two receptors do not belong to vertebrate CCK1R or CCK2R subfamilies.
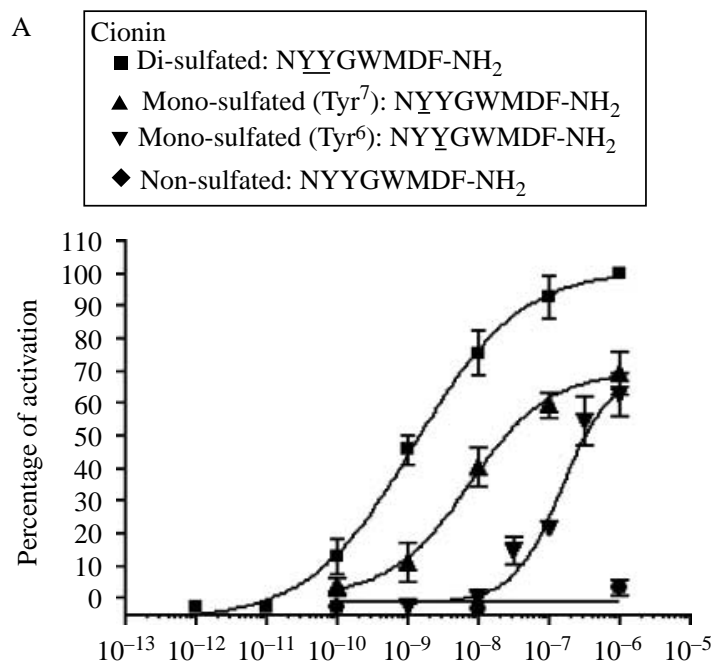

[M]
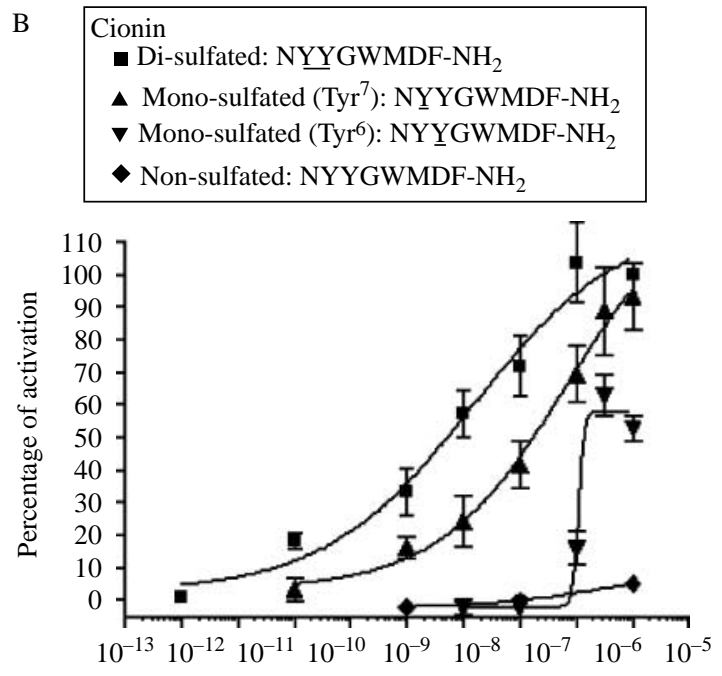

[M]

Figure 2 Activation of CioRs by cionin. A concentration-response curve in CioR1-expressing cells (A) and CioR2-expressing cells (B) is shown. The $\mathrm{Ca}^{2+}$ levels elicited by cionin and its derivatives are plotted. The $\mathrm{Ca}^{2+}$ level caused by $1 \mu \mathrm{M}$ cionin was defined as $100 \%$. The error bars denote S.E.M. $(n=5) . \underline{Y}$ indicates sulfated tyrosine. 
Table 2 Effects of cionin and cionin derivatives on intracellular calcium levels. Monosulfated cionin at positions 2 and 3 from the $\mathrm{N}$-terminus was described as $3 \Delta \mathrm{SO}_{3}$-cionin and $2 \Delta \mathrm{SO}_{3}$-cionin respectively

\begin{tabular}{lll} 
& \multicolumn{2}{c}{$\mathbf{E C}_{\mathbf{5 0}}(\mathrm{nM})$} \\
\cline { 2 - 2 } & $\mathrm{CioR} 1$ & \\
\cline { 2 - 2 } $\begin{array}{l}\text { Ligands } \\
\text { Di-sulfated cionin }\end{array}$ & $1 \cdot 22$ & \\
$3 \Delta \mathrm{SO}_{3}$-cionin & $7 \cdot 43$ & $1 \cdot 47$ \\
$2 \Delta \mathrm{SO}_{3}$-cionin & $150 \cdot 8$ & $\mathrm{ND}$ \\
& & $\mathrm{ND}$ \\
\hline
\end{tabular}

ND, not detected.

\section{Activation of CioRs by cionin}

In an attempt to examine whether CioRs are authentic receptors for cionin, intracellular calcium ion levels were measured in response to cionin in HEK293-MSR cells expressing CioR1 or CioR2. Intracellular calcium ion accumulated in a cionin concentration-dependent manner (Fig. 2A and B). EC 50 values of cionin for CioR1 and CioR2 were calculated to be 1.22 and $1.47 \mathrm{nM}$ on a dose-response curve of calcium ion accumulation level respectively (Table 2). No calcium ion accumulation was detected in untransfected HEK293-MSR cells, confirming that cionin binds specifically to CioR1 or CioR2 (Supplementary Figure 1, see section on supplementary data given at the end of this article). In mammals, tyrosine sulfation of CCK is essential for binding to CCK1R (Dufresne et al. 2006), and thus, receptor activation by monosulfated and nonsulfated cionin synthetic derivatives was also measured. Monosulfated cionin derivatives at CioRs were less potent than di-sulfated cionin. Monosulfated cionin at positions 2 and 3 from the $\mathrm{N}$ terminus was described as $3 \Delta \mathrm{SO}_{3}$-cionin and $2 \Delta \mathrm{SO}_{3}$-cionin respectively. $3 \Delta \mathrm{SO}_{3}$-cionin exhibited more potent calcium ion mobilization than $2 \Delta \mathrm{SO}_{3}$-cionin at both receptors (Fig. $2 \mathrm{~A}$ and $\mathrm{B}$ ). $\mathrm{EC}_{50}$ values of $3 \Delta \mathrm{SO}_{3}$-cionin and $2 \Delta \mathrm{SO}_{3}$-cionin for CioR1 were $7 \cdot 43$ and $150 \cdot 8 \mathrm{nM}$ respectively (Table 2). Such pharmacological activities of $3 \Delta \mathrm{SO}_{3}$-cionin and $2 \Delta \mathrm{SO}_{3-}$ cionin at CioR 2 were also observed, although the $\mathrm{EC}_{50}$ values were not calculated due to the low activity (Fig. 2 and Table 2). Moreover, the efficacy and potency of $3 \Delta \mathrm{SO}_{3}$-cionin and $2 \Delta \mathrm{SO}_{3}$-cionin were also lower than those of di-sulfated (authentic) cionin (Fig. 2). In contrast, a nonsulfated cionin derivative exhibited no activity at either CioR1 or CioR2 (Fig. 2). Collectively, these results revealed that CioRs are authentic endogenous receptors of cionin and that the two sulfated tyrosines of cionin are requisite for activation of CioRs at physiological concentrations.

\section{Tissue distribution of cionin, cior 1 and cior2}

To elucidate the expression pattern of cionin, cior 1 and cior2, we first performed RT-PCR in various tissues of adult
C. intestinalis. The cionin gene was shown to be predominantly expressed in the neural complex, stomach, oral siphon, and atrial siphon (Fig. 3). cior1 and cior 2 mRNA were detected mainly in the neural complex, digestive organs, ovary, oral siphon and atrial siphon (Fig. 3). cior1 and cior2 showed different expression patterns in the digestive organs. cior 1 was found to be expressed in the stomach and middle intestine, whereas only very faint expression of cior 2 was detected in these tissues (Fig. 3).

\section{Expression of cionin in the central nervous system}

We also examined localization of the cionin mRNA by whole mount in situ hybridization of Ciona juveniles. Transcript of cionin was detected specifically in the cerebral ganglion of Ciona juveniles (Fig. 4A, B and C). In situ hybridization of the adult cerebral ganglion demonstrated the cionin gene expression in a number of neurons in the cortical layer where numerous neurons reside and several neurons in the medulla (Fig. 4D and E).

Cionin-positive cells were also observed by immunohistochemistry in the adult $C$. intestinalis neural complex. Cioninergic nerve fibers and cell bodies were specifically detected in the medullary core and cortical layer of the cerebral ganglion respectively (Fig. 4F and G). In contrast, no obvious signal was detected by the antigen-preabsorbed antibody, confirming specificity of the cionin antibody (Fig. $4 \mathrm{H}$ and I). Furthermore, whole mount immunohistochemistry of young adult $C$. intestinalis verified cionin

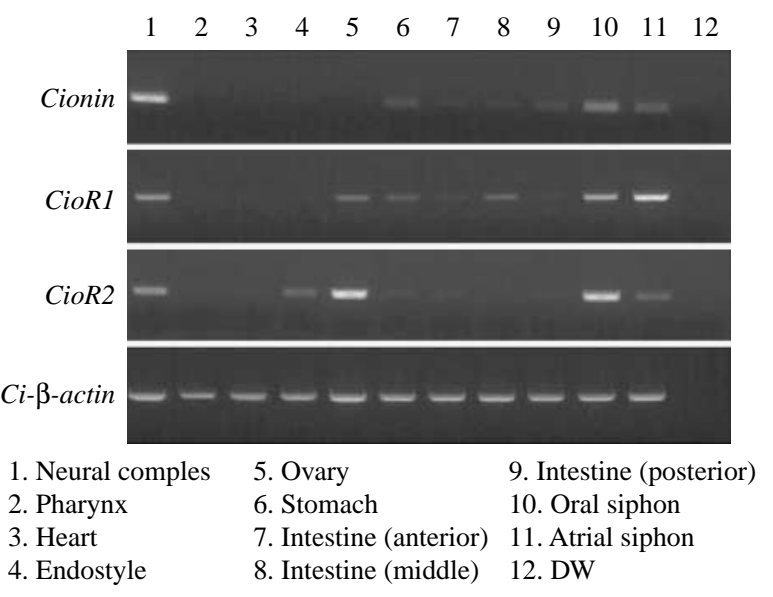

Figure 3 RT-PCR detection of cionin, cior 1 and cior 2 mRNA. The expressions of the cionin, cior 1 and cior 2 were examined in the neural complex (lane 1), pharynx (lane 2), heart (lane 3), endostyle (lane 4), ovary (lane 5), stomach (lane 6), anterior intestine (lane 7), middle intestine (lane 8), posterior intestine (lane 9), oral siphon (lane 10) and atrial siphon (lane 11) using RT-PCR. No band was detected in the absence of a template cDNA (DW, lane 12). $C i-\beta$-actin was amplified as an internal control. 

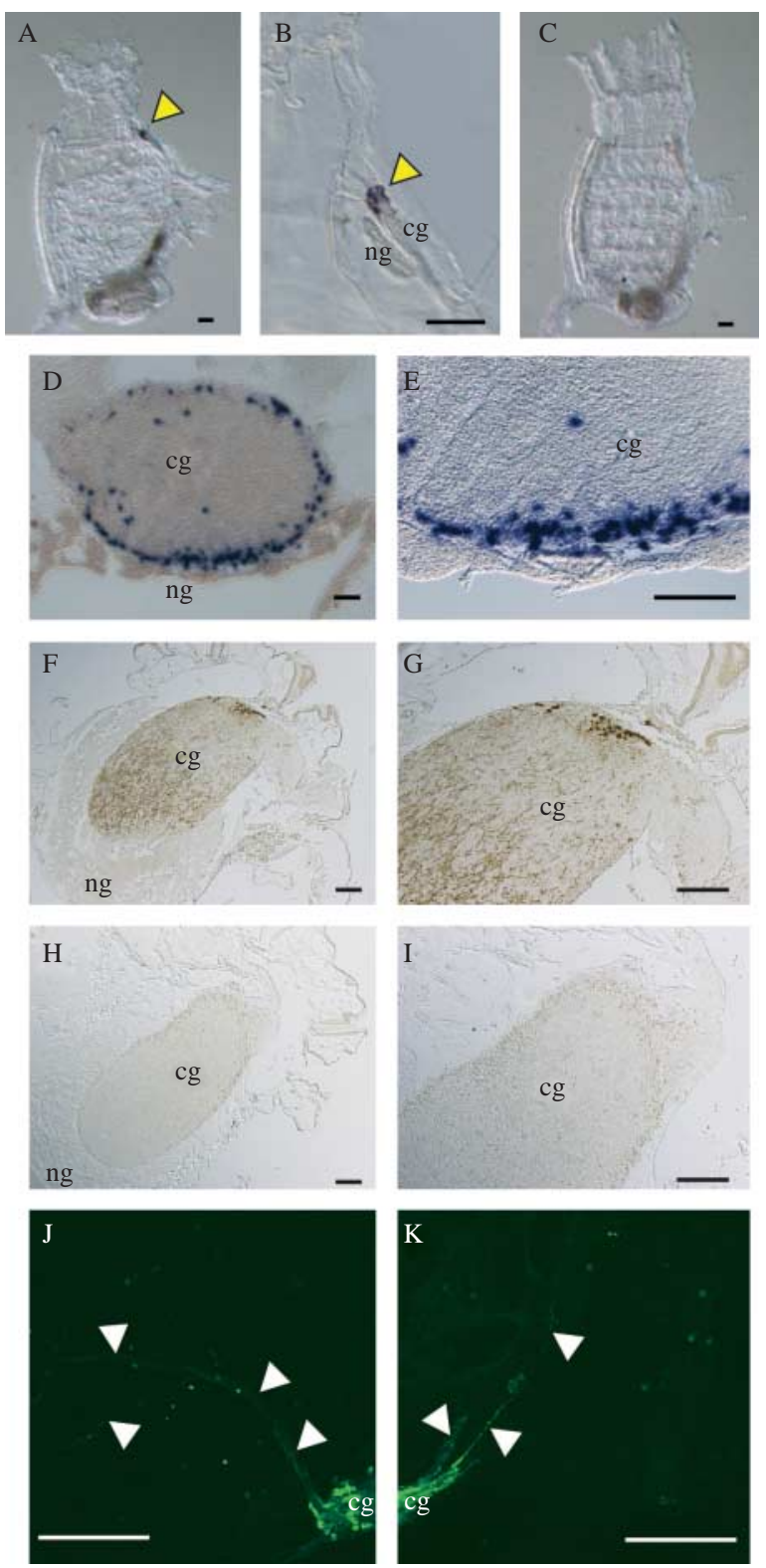

Figure 4 Localization of cionin mRNA and peptide in the neural complex. In situ hybridization analysis of cionin mRNA in the juvenile (A) and adult neural complex (D) is shown. The magnification of $(A)$ and $(D)$ is shown in (B) and (E) respectively. (C) In situ hybridization analysis in the juvenile using cionin mRNA sense probe. (A and B) Yellow arrowheads indicate cionin mRNA in the cerebral ganglion. Immunohistochemical analysis of the cionin peptide is shown in the adult neural complex (F) and the juvenile ( $\mathrm{J}$ and $\mathrm{K})$. Immunostaining of the adult neural complex using pre-absorbed antibody $(\mathrm{H})$ is demonstrated. $(\mathrm{G})$ and $(\mathrm{I})$ show the magnification in $(\mathrm{F})$ and $(\mathrm{H})$ respectively. $(\mathrm{J}$ and $\mathrm{K})$ Cioninergic nerve fibers are indicated by white arrowheads. cg, cerebral ganglion; ng, neural gland. Scale bars $100 \mu \mathrm{m}$. immunoreactive fibers projecting to the oral siphons and atrial siphons (Fig. 4J and K). Altogether, these results suggest that cionin is involved in multiple biological events including control of the siphons mainly in a neuropeptidergic manner.

\section{Discussion}

The CCK/gastrin family of peptides and their receptors are conserved in vertebrates (Johnsen et al. 1997). The evolution of the CCK/gastrin family has widely been studied throughout gnathostomes, indicating that CCK and gastrin diverged during the evolution of cartilaginous fish (Johnsen et al. 1997). CCK/ gastrin-like sulfated peptides have also been identified in protostome. Sulfakinin and neuropeptide-like protein 12 (NLP12) were isolated from protostomes, such as arthropods and nematodes respectively (Nachman et al. 1986, Nichols et al. 1988, Janssen et al. 2008). They display amino acid sequence similarity to CCK and cionin and exhibit similar physiological function to vertebrate CCK/gastrin (Janssen et al. 2008). Furthermore, their cognate receptors are also highly similar to vertebrate CCKRs (Staljanssens et al. 2011). However, the C-terminal tetrapeptide consensus sequence of sulfakinin (HisMet-Arg-Phe- $\mathrm{NH}_{2}$ ) and NLP12 (Pro-Leu-Gln-Phe- $\mathrm{NH}_{2}$ ) is different from that of vertebrate $\mathrm{CCK} /$ gastrin family peptides and cionin (Trp-Met-Asp-Phe- $\mathrm{NH}_{2}$ ). Moreover, DSK1 did not activate calcium accumulation in CioR-expressing cells (Supplementary Figure 1). These findings suggest that vertebrate $\mathrm{CCK} /$ gastrin and protostome analogs might have evolved from a common ancestor gene in independent lineages.

Such views led us to investigate the direct evolutionary origin of the structure and functions of the vertebrate $\mathrm{CCK} /$ gastrin in a protochordate, C. intestinalis, which is the closest invertebrate species to vertebrates (Delsuc et al. 2006, Putnam et al. 2008) and thus has been established as an animal model for developmental, evolutionary and endocrine research of chordates (Satoh et al. 2003, Sherwood et al. 2006, Kawada et al. 2010). In this context, molecular and functional characterization of cionin and its receptors is expected to provide crucial insight into the evolutionary process of the CCK/gastrin family as well as biological roles of cionin. In this study, we have elucidated the primary sequence, phylogenetic position, ligand reactivity, and tissue distribution of two cionin receptors, CioR 1 and CioR2, and also localization of cioninergic neurons. Phylogenetic analysis revealed that both receptors are orthologous to the vertebrate CCKRs and were generated via Ciona-specific gene duplication (Fig. 1B). Furthermore, both CioR 1 and CioR2, like vertebrate CCK1R and CCK2R, were shown to trigger the intracellular calcium mobilization in response to cionin, proving that CioR 1 and CioR2 are undoubtedly endogenous receptors for cionin (Fig. 2). Taken together, these results verify that the CCK/gastrin family is essentially conserved in a protochordate as well as in a vertebrate and that cionin and vertebrate $\mathrm{CCK} /$ gastrin were derived from a common ancestor. 
Pharmacological analysis demonstrated that monosulfated cionin derivatives are less potent activators of CioRs than cionin (Fig. 2). Moreover, nonsulfated cionin failed to activate CioRs (Fig. 2). Mammalian CCK1R does not bind to nonsulfated CCK and gastrin, which harbors a sulfated tyrosine at position 6 from the $\mathrm{C}$ terminus (note that a sulfated tyrosine is located at position 7 from the $\mathrm{C}$ terminus of $\mathrm{CCK}$ ) (Dufresne et al. 2006). In addition, CioRs and CCK1R, but not CCK2R, share an arginine residue in the extracellular loop 2 (Fig. 1A), which has been shown to participate in the specific recognition of a sulfated tyrosine of CCK by mutagenesis and photoaffinity study (Dufresne et al. 2006). In combination, this study supports the view that CioRs possess pharmacological features similar to mammalian CCK1R and that the molecular functionality of CCK1R is more closely related to that of a CioR-like prototype receptor than that of CCK2R.

The sulfated tyrosine at position 7 from the $\mathrm{C}$ terminus of cionin was shown to play a more important role in activation of CioRs than that occurring at position 6 , given that $3 \Delta \mathrm{SO}_{3}$-cionin, monosulfated cionin derivative harboring a sulfated tyrosine at position 7 from the $\mathrm{C}$ terminus, exhibited more prominent activation of CioRs than $2 \Delta \mathrm{SO}_{3}$-cionin, monosulfated cionin harboring a sulfated tyrosine at position 6 from the $\mathrm{C}$ terminus (Fig. 2). Notably, nonmammalian gastrins, like vertebrate CCK, conserve a sulfated tyrosine at position 7 from the C terminus (Johnsen et al. 1997, Johnsen 1998). Accordingly, chordate ancestors might have possessed a CCK-like original peptide with a sulfated tyrosine at position 7 from the $\mathrm{C}$ terminus, and the hybrid feature of cionin might have arisen in the Ciona evolutionary lineage. Furthermore, similar ligand selectivity between CioRs and CCK1R leads to the evolutionary scenario that the CCK and CCK1R pair is the evolutionarily original ligand-receptor pair in vertebrates.

Cionin was originally shown to be expressed in the digestive tract as well as in the central nervous system (Figs 3 and 4). Moreover, the expression of ciors was detected in the stomach and intestine (Fig. 4). Intriguingly, porcine CCK8 stimulated gastric enzyme secretion in an ascidian, Styela clava (Bevis \& Thorndyke 1981, Thorndyke \& Bevis 1984). In combination, cionin, like vertebrate $\mathrm{CCK} /$ gastrin, is also expected to serve as a digestive hormone.

Of particular interest is that ciors are expressed in the oral and atrial siphons (Fig. 3), and cioninergic neurons innervate to both of these siphons (Fig. $4 \mathrm{~J}$ and K). CCK inhibits feeding behavior in rodents, although the underlying molecular mechanism remains to be elucidated (Baldwin et al. 1998, Blevins et al. 2000). As C. intestinalis abolishes muscle contraction in the digestive organs due to the lack of muscle tissues in the stomach, esophagus and intestine (Goodbody 1975), water flow produced by the regulation of the siphons is expected to play a major role in C. intestinalis feeding behavior. Combined with these findings, the innervation of cioninergic neurons to the siphons and expression of cior genes in these tissues supports the view that cionin participates in the regulation of physiological functions of the siphons for feeding behavior. The physiological effect of cionin on the siphons is under investigation. Additionally, we observed the expression of ciors in the ovary, although neither biological action of CCK and gastrin nor the presence of CCK1R or CCK2R has ever been documented. Recently, we have substantiated that Ciona tachykinin, Ci-TK, induces vitellogenic oocyte growth via upregulation of gene expression of certain proteases (Satake et al. 2004, Aoyama et al. 2008, 2011), which is suppressed by a Ciona neurotensin-like peptide, Ci-NTLP6 (Kawada et al. 2011). These studies, combined with the expression of cior genes in the ovary, raise the possibility that brain-gut peptides or nonsexual peptide hormones, including CCK/gastrin, are involved in novel reproductive functions. The biological role of cionin in ovarian functions is currently being investigated in our laboratory.

In conclusion, we have shown the primary sequences, molecular phylogeny, activation and tissue distribution of the cionin receptors, CioR1 and CioR2, and identified the localization of cioninergic neurons. This study provides evidence that the cionin-CioR system is a molecular prototype for the vertebrate CCK/gastrin-CCKR system, and will pave the way for the exploration of not only biological roles of cionin but also molecular and functional evolution of the CCK/gastrin family.

\section{Supplementary data}

This is linked to the online version of the paper at http://dx.doi.org/10.1530/ JOE-11-0410.

\section{Declaration of interest}

The authors declare that there is no conflict of interest that could have prejudiced the impartiality of the research reported.

\section{Funding}

This study is financially supported in part by JSPS (to T S and H S).

\section{Acknowledgements}

The authors thank Ms Kazuko Hirayama and all members of Maizuru Fisheries Research Station for cultivation of the ascidians. The authors are also grateful to Dr Maki Shirae-kurabayashi (RIKEN Center for Developmental Biology) and Prof. Makoto Suematsu (Keio University and Suntory Foundation for Life Sciences) for technical advice of immunohistochemistry and fruitful comments on preparation of the manuscript respectively. All ascidians (C. intestinalis) were provided by Kyoto University through the National Bio-Resource Project of the MEXT, Japan.

\section{References}

Aoyama M, Kawada T, Fujie M, Hotta K, Sakai T, Sekiguchi T, Oka K, Satoh N \& Satake H 2008 A novel biological role of tachykinins as an up-regulator of oocyte growth: identification of an evolutionary origin of tachykininergic functions in the ovary of the ascidian, Ciona intestinalis. Endocrinology 149 4346-4356. (doi:10.1210/en.2008-0323) 
Aoyama M, Kawada T \& Satake H 2011 Localization and enzymatic activity profiles of the proteases responsible for tachykinin-directed oocyte growth in the protochordate, Ciona intestinalis. Peptides. (doi:10.1016/j.peptides. 2011.07.019)

Baldwin BA, Parrott RF \& Ebenezer IS 1998 Food for thought: a critique on the hypothesis that endogenous cholecystokinin acts as a physiological satiety factor. Progress in Neurobiology 55 477-507. (doi:10.1016/S0301-0082(98)00005-7)

Bevis PJ \& Thorndyke MC 1981 Stimulation of gastric enzyme secretion by porcine cholecystokinin in the ascidian Styela clava. General and Comparative Endocrinology 45 458-464. (doi:10.1016/0016-6480(81)90049-6)

Blevins JE, Stanley BG \& Reidelberger RD 2000 Brain regions where cholecystokinin suppresses feeding in rats. Brain Research 860 1-10. (doi:10.1016/S0006-8993(99)02477-4)

Crawley JN \& Corwin RL 1994 Biological actions of cholecystokinin. Peptides 15 731-755. (doi:10.1016/0196-9781(94)90104-X)

Delsuc F, Brinkmann H, Chourrout D \& Philippe H 2006 Tunicates and not cephalochordates are the closest living relatives of vertebrates. Nature 439 965-968. (doi:10.1038/nature04336)

Dockray GJ 2004 Clinical endocrinology and metabolism. Gastrin. Best Practice \& Research. Clinical Endocrinology and Metabolism 18 555-568. (doi:10.1016/j.beem.2004.07.003)

Dufresne M, Seva C \& Fourmy D 2006 Cholecystokinin and gastrin receptors. Physiological Reviews 86 805-847. (doi:10.1152/physrev.00014.2005)

Fan ZW, Eng J, Miedel M, Hulmes JD, Pan YC \& Yalow RS 1987 Cholecystokinin octapeptides purified from chinchilla and chicken brains Brain Research Bulletin 18 757-760. (doi:10.1016/0361-9230(87)90211-5)

Folsch UR, Winckler K \& Wormsley KG 1978 Influence of repeated administration of cholecystokinin and secretin on the pancreas of the rat. Scandinavian Journal of Gastroenterology 13 663-671. (doi:10.3109/ 00365527809181779)

Fritsch HA, Van Noorden S \& Pearse AG 1982 Gastro-intestinal and neurohormonal peptides in the alimentary tract and cerebral complex of Ciona intestinalis (Ascidiaceae). Cell and Tissue Research 223 369-402. (doi:10.1007/BF01258496)

Goodbody I 1975 The physiology of ascidians. Advances in Marine Biology 12 1-149.

Higgins DG \& Sharp PM 1988 CLUSTAL: a package for performing multiple sequence alignment on a microcomputer. Gene 73 237-244. (doi:10.1016/ 0378-1119(88)90330-7)

Janssen T, Meelkop E, Lindemans M, Verstraelen K, Husson SJ, Temmerman L, Nachman RJ \& Schoofs L 2008 Discovery of a cholecystokinin-gastrinlike signaling system in nematodes. Endocrinology 149 2826-2839. (doi:10. 1210/en.2007-1772)

Johnsen AH 1994 Identification of cholecystokinin from frog and turtle. Divergence of cholecystokinin and gastrin occurred before the evolution of amphibia. European Journal of Biochemistry 224 691-702. (doi:10.1111/j. 1432-1033.1994.00691.x)

Johnsen AH 1998 Phylogeny of the cholecystokinin/gastrin family. Frontiers in Neuroendocrinology 19 73-99. (doi:10.1006/frne.1997.0163)

Johnsen AH \& Rehfeld JF 1990 Cionin: a disulfotyrosyl hybrid of cholecystokinin and gastrin from the neural ganglion of the protochordate Ciona intestinalis. Journal of Biological Chemistry 265 3054-3058.

Johnsen AH, Jonson L, Rourke IJ \& Rehfeld JF 1997 Elasmobranchs express separate cholecystokinin and gastrin genes. PNAS 94 10221-10226. (doi:10.1073/pnas.94.19.10221)

Kawada T, Sekiguchi T, Sakai T, Aoyama M \& Satake H 2010 Neuropeptides, hormone peptides, and their receptors in Ciona intestinalis: an update. Zoological Science 27 134-153. (doi:10.2108/zsj.27.134)

Kawada T, Ogasawara M, Sekiguchi T, Aoyama M, Hotta K, Oka K \& Satake H 2011 Peptidomic analysis of the central nervous system of the protochordate, Ciona intestinalis: homologs and prototypes of vertebrate peptides and novel peptides. Endocrinology 152 2416-2427. (doi:10.1210/en.2010-1348)

Kurokawa T, Suzuki T \& Hashimoto H 2003 Identification of gastrin and multiple cholecystokinin genes in teleost. Peptides 24 227-235. (doi:10.1016/S0196-9781(03)00034-2)

Marvik R, Johnsen AH, Rehfeld JF, Sandvik A \& Waldum HL 1994 Effect of cionin on histamine and acid secretion by the perfused rat stomach. Scandinavian Journal of Gastroenterology 29 591-594. (doi:10.3109/ $00365529409092477)$
Monstein HJ, Thorup JU, Folkesson R, Johnsen AH \& Rehfeld JF 1993 cDNA deduced procionin. Structure and expression in protochordates resemble that of procholecystokinin in mammals. FEBS Letters 331 60-64. (doi:10.1016/0014-5793(93)80297-8)

Moran TH \& Schwartz GJ 1994 Neurobiology of cholecystokinin. Critical Reviews in Neurobiology 9 1-28.

Nachman RJ, Holman GM, Haddon WF \& Ling N 1986 Leucosulfakinin, a sulfated insect neuropeptide with homology to gastrin and cholecystokinin. Science 234 71-73. (doi:10.1126/science.3749893)

Nichols R, Schneuwly SA \& Dixon JE 1988 Identification and characterization of a Drosophila homologue to the vertebrate neuropeptide cholecystokinin. Journal of Biological Chemistry 263 12167-12170.

Nilsson IB, Svensson SP \& Monstein HJ 2003 Molecular cloning of a putative Ciona intestinalis cionin receptor, a new member of the CCK/gastrin receptor family. Gene 323 79-88. (doi:10.1016/j.gene.2003.09.002)

Ogasawara M, Sasaki A, Metoki H, Shin-i T, Kohara Y, Satoh N \& Satou Y 2002 Gene expression profiles in young adult Ciona intestinalis. Development Genes and Evolution 212 173-185. (doi:10.1007/s00427-002-0230-7)

Putnam NH, Butts T, Ferrier DE, Furlong RF, Hellsten U, Kawashima T, Robinson-Rechavi M, Shoguchi E, Terry A, Yu JK et al. 2008 The amphioxus genome and the evolution of the chordate karyotype. Nature 453 1064-1071. (doi:10.1038/nature06967)

Saitou N \& Nei M 1987 The neighbor-joining method: a new method for reconstructing phylogenetic trees. Molecular Biology and Evolution 4 406-425.

Satake H, Ogasawara M, Kawada T, Masuda K, Aoyama M, Minakata H, Chiba T, Metoki H, Satou Y \& Satoh N 2004 Tachykinin and tachykinin receptor of an ascidian, Ciona intestinalis: evolutionary origin of the vertebrate tachykinin family. Journal of Biological Chemistry 279 53798-53805. (doi:10.1074/jbc.M408161200)

Satoh N, Satou Y, Davidson B \& Levine M 2003 Ciona intestinalis: an emerging model for whole-genome analyses. Trends in Genetics 19 376-381. (doi:10.1016/S0168-9525(03)00144-6)

Schjoldager B, Jorgensen JC \& Johnsen AH 1995 Stimulation of rainbow trout gallbladder contraction by cionin, an ancestral member of the CCK/gastrin family. General and Comparative Endocrinology 98 269-278. (doi:10.1006/ gcen.1995.1069)

Sherwood NM, Tello JA \& Roch GJ 2006 Neuroendocrinology of protochordates: insights from Ciona genomics. Comparative Biochemistry and Physiology. Part A, Molecular and Integrative Physiology 144 254-271. (doi:10.1016/j.cbpa.2005.11.013)

Sonobe K, Sakai T, Satoh M, Haga N \& Itoh Z 1995 Control of gallbladder contractions by cholecystokinin through cholecystokinin-A receptors in the vagal pathway and gallbladder in the dog. Regulatory Peptides $6033-46$. (doi:10.1016/0167-0115(95)00117-0)

Staljanssens D, Azari EK, Christiaens O, Beaufays J, Lins L, Van Camp J \& Smagghe G 2011 The CCK(-like) receptor in the animal kingdom: functions, evolution and structures. Peptides 32 607-619. (doi:10.1016/j. peptides.2010.11.025)

Tamura K, Dudley J, Nei M \& Kumar S 2007 MEGA4: Molecular Evolutionary Genetics Analysis (MEGA) software version 4.0. Molecular Biology and Evolution 24 1596-1599. (doi:10.1093/molbev/msm092)

Thorndyke MC \& Bevis PJ 1984 Comparative studies on the effects of cholecystokinins, caerulein, bombesin 6-14 nonapeptide, and physalaemin on gastric secretion in the ascidian Styela clava. General and Comparative Endocrinology 55 251-259. (doi:10.1016/0016-6480(84)90109-6)

Wu SV, Walsh JH, Campbell BJ \& Dimaline R 1995 Molecular characterization and physiological regulation of a TATA-less gene encoding chicken gastrin. European Journal of Biochemistry 230 439-446. (doi:10. 1111/j.1432-1033.1995.0439h.x)

Received in final form 24 January 2012

Accepted 30 January 2012

Made available online as an Accepted Preprint 30 January 2012 